\title{
Trabzon Bölgesel İnovasyon Sisteminin Firma İnovasyon Performansı Üzerindeki Etkisi*
}

\author{
Ezgi BADAY YILDIZ ${ }^{1}$ \\ Yeşim DINDAROĞLU ${ }^{2}$ \\ Ceylan KAMBER ${ }^{3}$
}

ÖZ: Günümüzde bir firmanın piyasada meydana gelen değişikliklere karşı olan duyarlılı̆̆ı ve farklılaşabilmek adına gösterdiği inovasyon çabaları rekabet ortamında üstünlük sağlayabilmek adına en önemli unsurlar olarak görülmektedir. Söz konusu üstünlüğ̈̈ elde etmek, firma inovasyon performansının arttırlmasından geçmektedir. Firma inovasyon performansını etkileyen en önemli unsurlardan biri ise firmanın içinde bulunduğu inovasyon sistemi olarak kabul edilmektedir. Bu bilgiler doğrultusunda, çallşmanın temel amacı Trabzon Bölgesel Inovasyon Sistemi'nin, Trabzon'da faaliyet gösteren firmaların inovasyon performanslarl üzerindeki etkisini incelemektir. Belirtilen amaç doğrultusunda Trabzon'da yerleşik 160 firmaya uygulanmış olan inovasyon anketi verisi yapısal eşitlik modellemesi kullanılarak incelenmiştir. Elde edilen bulgulara göre, kurumlarla yapılan işbirliği ve rekabet avantajı inovasyon performansını pozitif, ekosistemden kaynaklı engeller ise inovasyon performansını negatif yönde etkilemektedir.

Anahtar Sözcükler: Bölgesel İnovasyon Sistemi, Yapısal Eşitlik Modellemesi

Jel Kodlart: C30, C38, R58, O31

\section{The Impact of Trabzon Regional Innovation System on Firm Innovation Performance}

\begin{abstract}
Today, the sensitivity of a firm to the changes in the market and its innovation efforts in order to differentiate are seen as the most important elements in order to gain superiority in the competitive environment. Achieving this advantage passes from enhancing innovation performance. One of the most important factors affecting innovation performance is the innovation system in which the company is located. In line with this information, the main purpose of this study is to examine the effect of the Trabzon Regional Innovation System on the innovation performance of firms operating in Trabzon. For this purpose, the innovation survey applied to 160 firms located in Trabzon data has been analyzed using structural equation modeling. According to the findings, cooperation and competitive advantage with institutions positively affect innovation performance, while barriers of the ecosystem influence innovation performance negatively.
\end{abstract}

Keywords: Regional Innovation System, Structural Equation Modeling. Jel Codes: C30, C38, R58, O31

Geliş Tarihi / Received: 02/08/2019

Kabul Tarihi / Accepted: 21/09/2019

\footnotetext{
* Bu çalışma, Ceylan KAMBER tarafindan KTÜ SBE İktisat Yüksek Lisans Programı kapsamında Dr. Öğr. Üyesi Ezgi BADAY YILDIZ danışmanlığında yürütülen "Bölgesel İnovasyon Sistemi: Trabzon Örneği” başlıklı yüksek lisans tezinden türetilmiştir.

1 Dr. Öğr. Üyesi, Karadeniz Teknik Üniversitesi, İktisat Bölümü, eyildiz@ktu.edu.tr, orcid.org/0000-0002-5975-3803

2 Dr. Öğr. Üyesi, Karadeniz Teknik Üniversitesi, İktisat Bölümü, yatasoy@ktu.edu.tr, orcid.org/0000-0001-8315-7908

3 Yüksek Lisans Öğrencisi, Karadeniz Teknik Üniversitesi, Sosyal Bilimler Enstitüsü, İktisat Anabilim Dalı, ckamber@hotmail.com, orcid.org/0000-0002-3630-7819.
} 


\section{Giriş}

Dünyada ekonomik, siyasal, sosyo-kültürel ve teknolojik alanda yaşanan gelişmeler firmalar için de değişim ihtiyacını kaçınılmaz bir hale getirmiştir. Bu değişime karşı firmaların varlıklarını sürdürebilmeleri açısından inovasyon faaliyetlerine yönelmeleri gerekmektedir. Ayrıca firmalar dinamik bir çevre içinde yer aldıklarından dolayı inovasyon performansları da birçok değişken tarafından olumlu ve olumsuz olarak etkilenmektedir. Güçlü bir ulusal ve bölgesel inovasyon sistemi ise, inovasyon performansının arttırılmasını sağlayan en önemli unsurlar arasında yer almaktadir.

İnovasyonda sistem yaklaşımı; bilginin ekonomik ve toplumsal faydaya dönüştürülmesi sürecini sağlayan tüm kurum, kuruluş ve paydaşların oluşturduğu bir ağ yapısı (network) olarak tanımlanmaktadır. Güçlü bir inovasyon sisteminin varlığı etkin ulusal ve bölgesel inovasyon sistemlerinin oluşturulmasına bağlıdır. $\mathrm{Bu}$ nedenle inovasyon faaliyetlerinin arttırılmasina odaklanmadan önce, bu faaliyetlerin gerçekleşmesine zemin hazırlayan ekosistemin, bir başka değişle ulusal ve bölgesel inovasyon sisteminin incelenerek, bu sistemin kırılganlıklarının tespit edilmesi ve tespit edilen kırılganlıkların giderilmesi gerekmektedir.

1990'lı yılların başında inovasyon sistemi teorisinin ayrı bir alanı olarak ortaya atılan bölgesel inovasyon sistemi (BİS), ulusal inovasyon sisteminin (UIS'in) bölgesel kalkınmaya uygulanması sonucu gündeme gelen bir yapı bütünü olup; yerel-kurumsal dinamiklerin bölgesel inovasyon üzerinde oynadığı rolü açıklamaktadır. BİS' in önemi kısmen bölgesel farklılıkların giderilmesine yönelik yeni politikalara duyulan ihtiyacın bir sonucudur.

Küresel rekabette inovasyona verilen önemin bir gereği olarak, gelişen ve değişen çevre şartlarına göre bölgesel inovasyon sistemi teşvik ve politikalarının da eş anlı olarak gözden geçirilmesi birçok ülke hedeflerinde ön sıralarda yer almaktadır. Ayrıca inovasyon engelleri için çözüm önerileri üretmek ve bu çözümlerle ekosistemi canlandırmak için de araştırmalar yapılmaktadır.

Nitekim ulusal ve uluslararası literatür dikkate alındığında ulusal-bölgesel inovasyon sistemini konu edinen birçok çalışma bulunmaktadır. Özellikle ulusal literatürde BİS'e odaklanan çalışmalar incelendiğinde genellikle bir veya birkaç bölgenin inovasyon sisteminin incelendiği görülmekle birlikte, Trabzon İli’nin bölgesel inovasyon sistemini inceleyen çalışma sayısı oldukça sınırlıdır.

$\mathrm{Bu}$ bilgiler 1şı̆̆ında, çalışmanın temel amacı Trabzon Bölgesel İnovasyon Sistemi'nin Trabzon'da faaliyet gösteren firmaların inovasyon performansları üzerindeki etkisini incelemektir. Belirtilen amaç doğrultusunda beş bölümden oluşan çalışmada giriş bölümünün ardından, ikinci bölümünde bölgesel inovasyon sistemi tanıtılarak, teorik ve ampirik literatürden örnekler verilmiştir. Araştırma metodolojisine ayrılan üçüncü bölümün ardından, dördüncü bölümde analiz sonuçları özetlenmiştir. Sonuç bölümünde ise bulgulara yönelik genel bir değerlendirmeye yer verilmiştir. 


\section{Kavramsal Çerçeve ve Literatür}

Bölgesel ortamların ve yakınlığın inovasyon dinamikleri için hayati olduğunu ve inovasyonun kendisinin yerel bir süreç olduğunu savunan Doloreux (2004:174)'e göre, inovasyon farklı aktörler arasındaki çeşitli etkileşimlerden kaynaklanan bir süreçtir. Bu nedenle diğer üreticiler, tedarikçiler, üniversiteler, araştırma enstitüleri ve yerel destek kuruluşları ile kurulan dış ilişkiler yenilik ve teknolojik verimlilik için yeni fikirlerin kaynağı olarak kabul edilmektedir. Bu görüş son yıllardaki araştırmalara da konu olmuş ve farklı terminolojilerle açıklanmaya çalışılmıştır. Kronolojik sırayla kullanılan terminolojiler şu şekildedir: "yenilikçi çevre" (Maillat, 1998; Crevoisier ve Camagni, 2001); "sanayi bölgesi" (Pyke, 1992); “öğrenme bölgesi” (Florida, 1995; Morgan, 1997; Maillat ve Ke’bir, 1999); “endüstriyel küme”(Porter, 1998, Maskell, 2001) ve "bölgesel inovasyon sistemi" (Cooke, 1992; Braczyk vd., 1998; De la Mothe ve Paquet, 1998; Cooke vd., 2000; Doloreux, 2002).

Bölgesel İnovasyon Sistemi (BİS) terminolojisi, 1990'lı yılların başında inovasyon sistemleri teorisinin ayrı bir alanı olarak iki ana fikirle ortaya çıkmıştır (Poruchnyk ve Brykova, 2006: 134-135): i.inovasyon faaliyetinin sistematik doğası; ii. inovasyon sürecinin bölgesel boyutu.

İlk fikir yani inovasyon faaliyetinin sistematik doğasının teorik temelleri Freeman (1987), Lundvall (1992) ve Nelson (1993) ile UIS'in çalışma ilkelerinin incelenmesine dayandırılmıştır.

İnovasyon sürecinin bölgesel doğası olan BİS ise ikinci temel fikirdir. Bir ülkenin küresel pazarda inovasyonda uzun vadede rekabet avantajı sağlamasında, bölgesel düzeydeki faktörlerin kilit rol oynadığı argümanına dayanmaktadır. Böylece Cooke (1992) öncülüğünde küresel olarak rekabet edebilmek için yerel olarak iş birliği yapma gerekliliğini vurgulayan yeni bir bölgesel bilim dalı olarak ortaya çıkmıştır. Cooke (1992), UİS'i bölgesel olarak indirgemiş ve BİS kavramı tanımına ilk kez yer vermiştir. BİS'in gelişimi ve dolayısıyla bölgeler arasındaki farklılıkların giderilmesi günümüzde önemli bir konu haline gelmiştir.

İskandinav ekonomisti B. Lundvall (1992), bölgelerin bölgesel inovasyon ağları ile yüksek teknoloji ürünleri oluşturarak ve işbirliği yapılan araştırma enstitülerinin zenginleştirici bilgilerini kullanarak, bölgesel seviyede önemli bir üretici işlevi gerçekleştirdiğini savunmaktadır. BİS kavramını Lundvall'a paralel olarak tanımlayan Wiig (1996)'e göre BİS, UİS'e dayanmaktadır ve bu nedenle bölgedeki inovasyon kapasitesini belirleyen yerel olarak kurulmuş kurumlarla ilişkilidir.

Bölgesel inovasyon sisteminin daha çok, bir ülkenin bölgelerinin sistemlerini analiz etme bağlamındaki teorik temelleri ise Asheim ve Isaksen (1997), Bracyzk vd.(1998), Freeman (2002), Asheim vd. (2003), Gertler ve Asheim (2005) gibi bilim insanlarının eserlerinde ortaya çıkmıştır. $\mathrm{Bu}$ bağlamda takip eden araştırmacılar genellikle bölgesel inovasyon sistemi kavramına nicel bir temel kazandırmaya çalışmışlardır. Örneğin, Wiig ve Wood (1995) Norveç'in 
merkezindeki bir kıyı bölgesi olan Møre ve Romsdal'daki imalatçı firmalar arasında yapılan yenilikçi faaliyetlerini; Fritsch (2001), üç Alman bölgesinde HannoverBrunswick-Göttingenttingen imalat firmalarının işbirliği ilişkilerini; Asheim ve Isaksen (2002), Norveç'te Hortren Jæren Sunnmøre bölgelerinde bulunan gemi inşaatı, makine mühendisliği ve elektronik endüstrisindeki firmaların, rekabet edebilirliklerini ve işbirliği ağlarını; Poruchnyk ve Brykova (2006), BİS'in temel çalışma prensiplerini ve Ukrayna bölgelerinin inovasyon performanslarını incelemişlerdir.

\section{Araştırma Metodolojisi: Yapısal Eşitlik Modellemesi}

Trabzon Bölgesel İnovasyon Sistemi'nin firma inovasyon performansı üzerindeki etkilerini ampirik olarak inceleyebilmek amaciyla son y1llarda sosyal bilimlerde yaygın olarak kullanılan Yapısal Eşitlik Modellemesi (YEM) Analizi ${ }^{4}$ tercih edilmiştir. Bu tercihin temel sebebi, YEM analizinin, çok değişkenli veriler arasındaki ilişkileri incelemek için iyi bilinen bir teknik olmasıdır (Bentler ve Yuan, 1999: 181).

Ayrıca inovasyonda sistem yaklaşımı gözlenen değişkenlerin yanında birçok gizil yapı içermektedir ve teorinin tam olarak modellenebilmesi açısından ilgili gizil yapıların da modele dâhil edilmesi gereklidir. Gizil yapılar (değişkenler veya faktörler) doğrudan gözlenemeyen veya ölçülmeyen değişkenlerdir. Fakat anketler vb. araçlar kullanarak gerçekten ölçtüğümüz bir dizi gözlemlenmiş değişkenden çıkarılabilirler (Schumacker ve Lomax, 2010:3). Bu açıdan değerlendirildiğinde YEM analizinde, gizil yapılar da bilime konu olabilmektedir. Bu şekilde gerçek, araştırmaci tarafından teori perspektifinden resmedilmekte ve hipotezler test edilebilmektedir.

YEM Analizinin tarihsel gelişim süreci, kronolojik oluşum sırasına göre dört ilgili analizden oluşmaktadır. Bunlar: Regresyon Analizi; Yol Analizi; Doğrulayıcı Faktör Analizi ve Yapısal Eşitlik Modellemeleridir (Schumacker ve Lomax, 2010:2).

İlgili analizleri içeren standart bir YEM uygulaması altı aşamada gerçekleştirilir: I) Teoriye dayanan bir model belirlenir; II) Model tanımlanır; III) Veriler toplanır; IV) Model tahmin edilir; V) Model uyum istatistikleri değerlendirilir; VI) Modelin modifikasyonu sağlanır (Weston ve Gore, 2006: 729; Schumacker ve Lomax, 2010: 197-207). Son olarak nihai modelin parametre tahminleri teorik çerçeveye göre yorumlanır. YEM Analizi aşamaları Şekil 1'de sunulmuştur.

\footnotetext{
${ }^{4}$ YEM analizi gerçekleştirilirken AMOS Programı kullanılmıştır.
} 
Şekil 1: YEM Temel Aşamaları

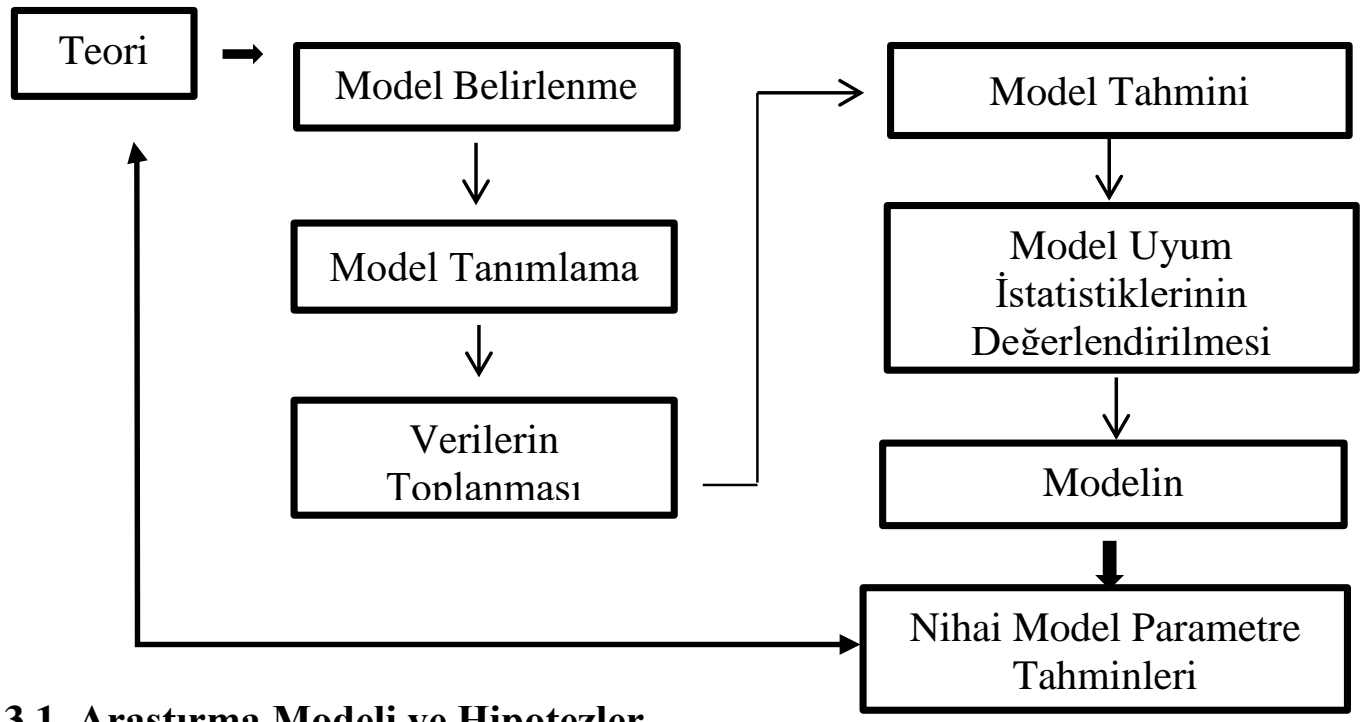

\subsection{Araştırma Modeli ve Hipotezler}

YEM analizinin ilk aşaması sağlam bir teorik temele dayalı araştırma modelinin oluşturulmasıdır. Bölgesel inovasyon sistemi literatürü göz önünde bulundurularak oluşturulan araştırma modeli Şekil 2'de yer almaktadır. Buna göre, bağımlı değişken firma inovasyon performansıdır. Bölgesel inovasyon sistemini temsilen diğer kurumlarla yapılan işbirliği, ekosistemden kaynaklanan engeller ve firmanın diğer kurumlara göre rekabet avantajı bağımsız değişkenler olarak modele dâhil edilmiştir.

Şekil 2: Araştırma Modeli

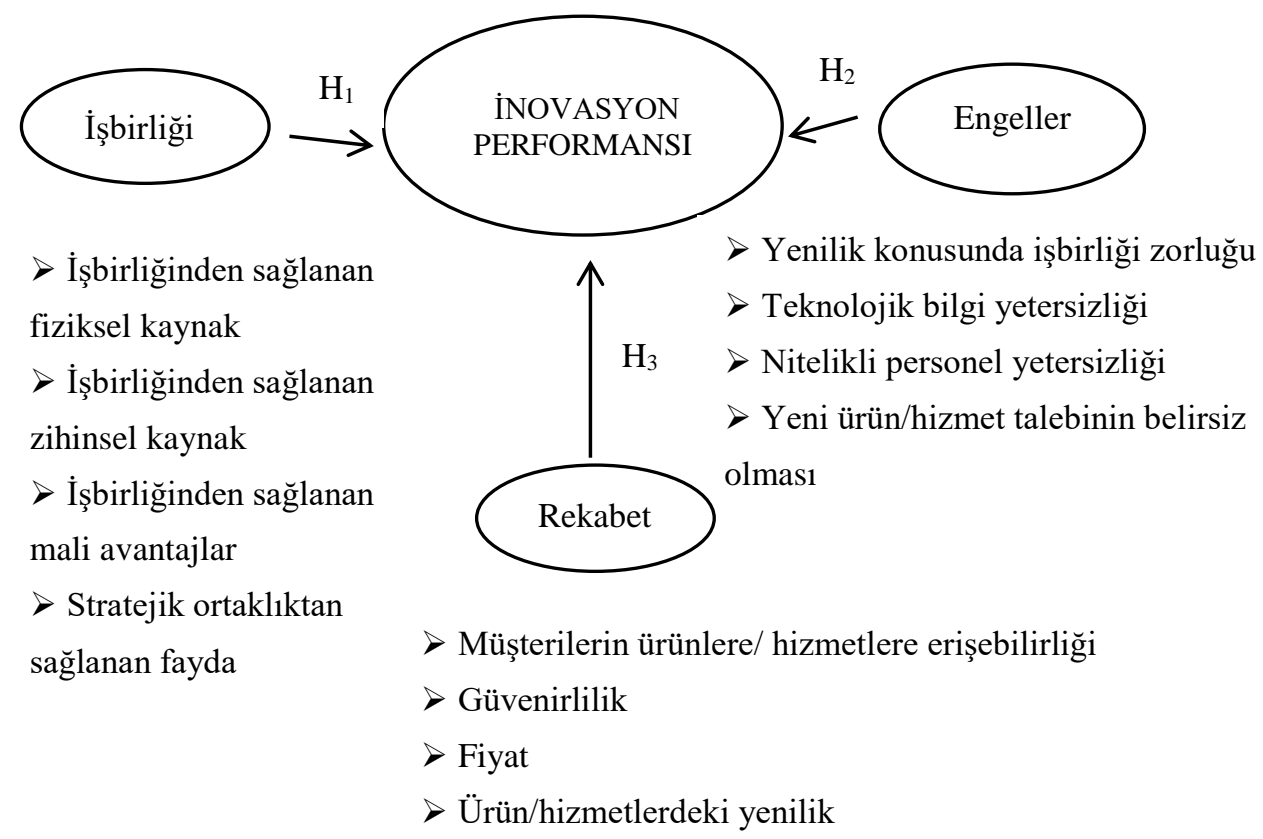


Bölgesel inovasyon sisteminin firma inovasyon performansı üzerindeki etkisini test etmek üzere üç hipotez oluşturulmuştur:

$\mathrm{H}_{1}$ : İşbirliği ile inovasyon performansı arasındaki yol katsayısı pozitif ve istatistiksel olarak anlamlıdır.

$\mathrm{H}_{2}$ : Engeller ile inovasyon performansı arasındaki yol katsayısı negatif ve istatistiksel olarak anlamlıdır.

$\mathrm{H}_{3}$ : Rekabet ile inovasyon performansı arasındaki yol katsayısı pozitif ve istatistiksel olarak anlamlıdır.

\subsection{Araştırma Modeli Tanımlamalar}

Araştırma modelinde bağımlı gizil değişken firma inovasyon performansıdır. Firma inovasyon performansının ölçülmesine ilişkin ilgili literatürde ortak bir görüş olmamakla birlikte, yaygın kullanım patent ve marka sayıları gibi fikri mülkiyet haklarına dayalı değerlendirmedir. Ancak tek başına patent değişkeninin inovasyon performansını değerlendirmede yetersiz kalacağı yönünde eleştiriler de mevcuttur. Patent verilerinin kalitesi veya güvenilirliğine ilişkin tartışmalara dayanan bu eleştiri iki nedenden kaynaklanmaktadır (Akçomak ve Kalaycı, 2016: 110): İlk olarak, pek çok yenilik patentlenmemiştir; ikinci olarak, çoğu patent ticarileşmeden raflarda kalabilmektedir.

Tüm bu eleştirilere rağmen, Katila (2000), yeniliğin ölçülmesinde patentlerin kullanımını ve ampirik eksikliklerini araştırdığı çalışmasında, patentlerin inovasyon performansını ölçmede yararlı bir yol olduğu sonucuna varmıştır. Katila (2000:3), patent verisinin rakiplerin faaliyetlerini izlemek, Ar-Ge organizasyonlarında bir performans değerlendirme sistemi oluşturmak ve belirli bir teknolojik eğilimi tanımlamak için kullanılabileceğini vurgulamaktadır. $\mathrm{Bu}$ açıklamalar doğrultusunda, mevcut çalışmada firma inovasyon performansı patent ve marka sahipliği ile ölçülmektedir.

Bölgesel inovasyon sistemini temsilen araştırma modelinde işbirliği, rekabet ve engeller olmak üzere üç bağımsız gizil değişken yer almaktadır. Bağımsız gizil değişkenlerin belirlenmesinde bölgesel inovasyon sistemi literatürü göz önünde bulundurulmuştur. İşbirliğinin firma inovasyon performansı üzerindeki etkisini inceleyen çalışmalar: Larsson ve Malmberg (1999), Hadjimanolis (1999), Brioschi vd. (2002), Diez (2002), Bullinger vd. (2004), Doloreux (2004), Becker ve Diez (2004), Liefner vd. (2006), Nieto ve Santamaria (2007), Kaminski vd. (2008), Aschhoff ve Schmidt (2008), Zeng (2010), Faria vd. (2010), Burmaoğlu ve Şeşen (2011), Özgür Güler ve Kanber (2011), Berchicci (2013), Tomlinson ve Fai (2013), Robin ve Schubert (2013), Seyfettinoğlu ve Taşdoğan (2014), Wu (2014), Findık ve Beyhan (2015), Kalay vd. (2015), Estrada vd. (2016).

Rekabet avantajının firma inovasyon performansı üzerindeki etkisini inceleyen çalışmalar: Nickell (1996), Blundell (1999), Nevo (2001), Petrin (2001), Ahn 
(2002), Aghion vd. (2005), Schmutzler (2009), Darai vd. (2010), Aghion vd. (2014), Karakaya vd. (2018).

Engellerin firma inovasyon performansı üzerindeki etkisini inceleyen çalışmalar: Hadjimanolis (1999), Galia vd. (2004), Iammarino vd. (2007), Madrid-Guijarro vd. (2009), Güler ve Kanber (2011), Pourkiani vd. (2013), Hölzl ve Janger (2013), Bartels vd. (2014), Corchuelo ve Mesías (2015), Coad vd. (2016), Sağ vd. (2016), Wang (2016), Madeira vd. (2017), Hartono ve Kusumawardhani (2018).

Araştırma modelinde yer alan bağımsız gizil değişkenlerden her biri dörder gözlenen değişken vasitasıyla ölçülmüştür. Diğer kurumlarla yapılan işbirliği değişkeninin ölçümünde, işbirliğinden sağlanan fiziksel kaynaklar, zihinsel kaynaklar, mali avantajlar ve stratejik ortaklıktan sağlanan faydalar kullanılmıştır. Ekosistemden kaynaklanan engeller değişkeninin ölçümünde yenilik konusunda işbirliği zorluğu, teknolojik bilgi yetersizliği, nitelikli personel yetersizliği ve yeni ürün/hizmet talebinin belirsiz olması değişkenleri kullanılmıştır. Firmanın ekosistemdeki rekabet avantajı ise müşterilerin ürünlere/hizmetlere erişebilirliği, güvenirlilik, fiyat ve ürün/hizmetlerdeki rekabet avantajı değişkenleriyle ölçülmüştür. Araştırma modelinde yer alan gizil ve gözlenen değişkenlerin tanımlamaları Tablo 1'de yer almaktadır.

Tablo 1: Değişkenlerin Tanımları

\begin{tabular}{|l|l|}
\hline Değişken adı & Tanımı \\
\hline İnovasyon Performansı & I_PER \\
\hline Toplam ulusal patent sahiplĭgi & LPATENT \\
\hline Toplam ulusal marka sahipliği & LMARKA \\
\hline Rekabet & REKABET \\
\hline Müşterilerin ürünlere/hizmetlere erişebilirliği & R_UH \\
\hline Güvenirlilik & R_G \\
\hline Fiyat & R_F \\
\hline Ürün/hizmetlerdeki yenilik & R_IN \\
\hline İşbirliği & ISBIRLIGI \\
\hline İşbirliğinden sağlanan fiziksel kaynak & C_FK \\
\hline İşbirliğinden sağlanan zihinsel kaynak & C_ZK \\
\hline İşbirliğinden sağlanan mali avantajlar & C_ML \\
\hline Stratejik ortaklıktan sağlanan fayda & C_SO \\
\hline Engeller & ENGELLER \\
\hline Yenilik konusunda işbirliği zorluğu & O_C \\
\hline Teknolojik bilgi yetersizliği & O_TECH \\
\hline Nitelikli personel yetersizliği & O_NP \\
\hline Yeni ürün/hizmet talebinin belirsiz olması & O_TLBI \\
\hline L:logaritmik değerleri temsil eder. & \\
\hline
\end{tabular}




\subsection{Veri Toplama Aracı ve Yöntemi}

Araştırma modeli belirlenip, tanımlamalar yapıldıktan sonra YEM analizinin üçüncü aşaması verilerin elde edilmesidir. KOSGEB tarafından desteklenen ve Trabzon Ticaret ve Sanayi Odası tarafindan uygulanan “Trabzon'da Yenilikle Geleceğe Projesi” kapsamında yapılan "Ar-Ge ve Yenilik Anketi” verileri çalışmanın veri setini oluşturmaktadır. İlgili anket, Trabzon il sınırları içinde faaliyet gösteren, Trabzon Ticaret ve Sanayi Odası'na kayıtlı, kapasite raporu bulunan ve sektörel çeşitlilik gözetilerek seçilmiş 160 firmaya uygulanmıştır. Katılımc1 firmalar genellikle, Trabzon Teknokent'te ve organize sanayi bölgelerinde yerleşik ve 25 farklı sektörde faaliyet göstermektedirler. Firmalarda genellikle üst düzey yöneticiler ile görüşülerek, çoğu kapalı uçlu sorulardan oluşan anket uygulanmiştır.

\section{Model Tahmini ve Bulgular}

\subsection{Faktör Analizi Bulgular}

Model tahminin gerçekleştirilmesinde öncelikle her bir yapının indirgenmesi amacıyla açıklayıcı faktör analizi (EFA) gerçekleştirilmiştir. Faktörlerin güvenirlik analizi Cronbach's Alpha Katsayısı ile değerlendirildikten sonra YEM analizi prosedürüne uygun olarak, gözlenen değişkenlerin gizil yapıları ne kadar ifade ettiğinin belirlenmesi için doğrulayıcı faktör analizi (CFA) uygulanmıştır. Sonuçlar Tablo 2'de görülmektedir.

Tablo 2: Faktör Analizi Sonuçları

\begin{tabular}{|c|c|c|c|c|c|c|}
\hline Faktör & Değişkenler & EFA & CFA & \multicolumn{2}{|c|}{ Açıklanan Varyans \% } & Cronbach's Alpha \\
\hline \multirow{4}{*}{ Engeller } & O_TECH & .769 & 1.00 & \multirow{4}{*}{\multicolumn{2}{|c|}{29.463}} & \multirow{4}{*}{691} \\
\hline & O_C & .691 & .387 & & & \\
\hline & O_NP & .685 & .371 & & & \\
\hline & O_TLBI & .407 & .248 & & & \\
\hline \multirow{4}{*}{ İşbirliği } & C_ZK & .931 & .973 & \multirow{4}{*}{\multicolumn{2}{|c|}{14.146}} & \multirow{4}{*}{.944} \\
\hline & C_SO & .921 & .957 & & & \\
\hline & C_FK & .920 & .963 & & & \\
\hline & C_ML & .911 & .970 & & & \\
\hline \multirow{4}{*}{ Rekabet } & R_G & .725 & .882 & \multirow{4}{*}{\multicolumn{2}{|c|}{12.899}} & \multirow{4}{*}{.805} \\
\hline & R_UH & .724 & .464 & & & \\
\hline & R_F & .469 & .267 & & & \\
\hline & R_IN & .446 & .252 & & & \\
\hline \multicolumn{4}{|c|}{ Kümülatif Acıklanan Varvans } & \multicolumn{2}{|c|}{56.508} & \\
\hline \multicolumn{4}{|c|}{ KMO } & \multicolumn{2}{|c|}{.781} & \\
\hline \multirow{2}{*}{\multicolumn{4}{|c|}{ Bartlet's Test of Sphericity }} & Chi Squared & Df & Significance \\
\hline & & & & 723.557 & 66 & .000 \\
\hline
\end{tabular}

Faktör analizi sonuçlarına göre,

- Tüm yapılar için Bartlett'in küresellik testi, yeterli bir ilişki olduğunu göstermektedir (Sig. $=0.000<0.05$; Bartels vd., 2014). 
- Örneklemin yeterliliğini ölçen Kaiser-Meyer-Olkin (KMO) testi tatmin edici seviyede gerçekleşmiştir (0.78).

- Faktörlerin tanımlanması, temel bileșenler analizi ve Varimax dönüşümü ile gerçekleştirilmiştir. Açıklanan kümülatif varyans \%56.5 iken en yüksek açıklama oranına sahip faktör \%29.46 ile engeller faktörüdür.

- Faktör yüklerinin tamamı pozitif ve istatistiksel olarak anlamlıdır. Ayrıca önerilen değerin üzerindedir (0.30-0.40, Floyd ve Widaman, 1995).

- Cronbach's Alpha değerleri engeller, işbirliği ve rekabet faktörleri için sırasıyla 0.69-0.94-0.80 düzeyindedirler ve YEM analizi için önerilen değerden (0.6; Liao ve Rice, 2009; Bagozzi ve Yi,1988) yüksektirler.

\subsection{Yapısal Eşitlik Modellemesi ve Sonuçları}

Ön değerlendirmeler sonucu YEM analizi için yol diyagramı Şekil 3'de yer almaktadır. YEM yol diyagramında oklar denklemleri, ok yönleri ise bağımlı ve bağımsız değişkenleri temsil etmektedir. Oval şekiller gizil yapıları, dikdörtgen şekiller ise gizil yapıları etkilediği düşünülen gözlenen değişkenleri ifade etmektedir (Bartels vd., 2014:15).

Şekil 3: YEM Yol Diyagramı

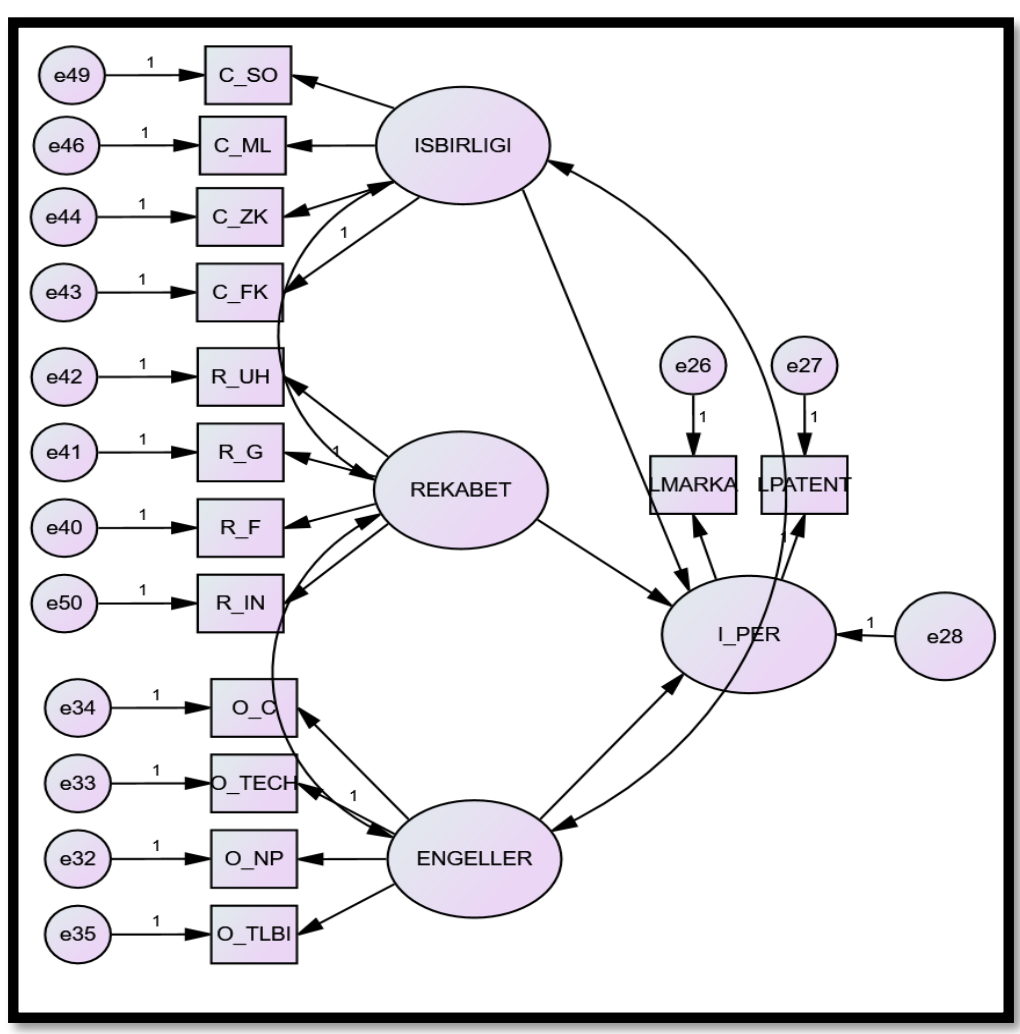

Model tahmininin maximum likelihood tahmincisi ile gerçekleştirilebilmesi için verilerin normal dağılım varsayımını sağlaması gereklidir. Verilerin tekil olarak 
çarpıklık (skew) ve basıklık (kurtosis) değerleri incelendiğinde genel olarak normal dağılım varsayımını sağladıkları tespit edilmiştir. Ancak özellikle bağımlı gizil değişkenin elde edilmesinde kullanılan gözlenen değişkenlerin (patent ve marka) ilgili değerlerinin George ve Mallery (2010)'in önerdiği -2/+2 aralığında olmayışı ve Multivariate c.r. değerinin (26.429) yüksek olması sebebiyle normal dağılım varsayımının sağlanamadığı sonucuna ulaşılmıştır. Bu nedenle Asymptotically Distribution-free Estimates tahmincisi kullanılmıştır.

Sonuçlar raporlanırken gizil yapılar arasındaki yol katsayıları ve model uyum istatistiklerine yer verilmiştir. Çeşitli model uyum istatistiklerine (Hu ve Bentler, 1999; Schumacker ve Lomax, 2010; Bartels vd., 2014) göre değerlendirme Tablo 3'de ve YEM analizi yol katsayıları Tablo 4'de yer almaktadır.

Tablo 3: Model Uyum istatistikleri

\begin{tabular}{|c|c|c|}
\hline Model Uyum İstatistiği & Değer & $\begin{array}{l}\text { Önerilen } \\
\text { Dĕ̆gr }\end{array}$ \\
\hline$\chi^{2} / \mathrm{df}$ test istatistiği & 1.312 & $\chi^{2} / \mathrm{df}<2$ \\
\hline Goodness of Fit Index (GFI) & 0.99 & GFI $>0.90$ \\
\hline Adjusted GFI (AGFI) & 0.99 & AGFI > 0.90 \\
\hline Normed Fit Index (NFI) & 0.978 & NFI $>0.90$ \\
\hline Comparative Fit Index (CFI) & 0.995 & $\mathrm{CFI}>0.95$ \\
\hline $\begin{array}{l}\text { Root Mean Square Error of Approximation } \\
\text { (RMSEA) }\end{array}$ & 0.044 & RMSEA $<0.05$ \\
\hline
\end{tabular}

Tablo 3'te birinci sütun uyum istatistiğinin türünü, ikinci sütun araştırma modelinin uyum istatistiği değerini ve üçüncü sütun önerilen karar ölçütünü göstermektedir. Buna göre, genel olarak varsayımsal modelin istatistiksel özellikleri yerine getirdiği ve örnekleme iyi uyum sağladığı sonucuna ulaşılmıştır.

Tablo 4: YEM Analizi Yol Katsayıları

\begin{tabular}{|c|c|c|c|c|c|c|}
\hline \multicolumn{4}{|c|}{ Hipotezler } & Yol Katsayıst & S.E. & $P$ \\
\hline $\mathrm{H}_{1}$ : & I_PER & $<--$ & ISBIRLIGI & .004 & .001 & $* * *$ \\
\hline $\mathrm{H}_{2}$ : & I_PER & $<--$ & ENGELLER & -.056 & .028 & .046 \\
\hline $\mathrm{H}_{3}$ : & I_PER & $<--$ & REKABET & .004 & .002 & .006 \\
\hline
\end{tabular}

Tablo 4'de birinci sütun hipotezleri (yol katsayısının yönünü), ikinci sütun yol katsayısı değerini, üçüncü sütun standart hatasını (S.E.) ve son sütun olasılık değerini göstermektedir.

Teorik modele göre $\mathrm{H}_{1}$ hipotezi diğer kurumlarla yapılan işbirliğinin firma inovasyon performansı üzerindeki etkisini temsil etmektedir. Bu ilişki için yol katsayıs1 (.004) pozitif ve istatistiksel olarak \%1 seviyesinde anlamlıdır. Bu nedenle $\mathrm{H}_{1}$ hipotezi desteklenmektedir. 
Teorik modele göre $\mathrm{H}_{2}$ hipotezi ekosistemden kaynaklanan engellerin firma inovasyon performansı üzerindeki etkisini temsil etmektedir. Bu ilişki için yol katsayıs1 (-.056) negatif ve istatistiksel olarak \%5 seviyesinde anlamlıdır. $\mathrm{Bu}$ nedenle $\mathrm{H}_{2}$ hipotezi desteklenmektedir.

$>$ Teorik modele göre $\mathrm{H}_{3}$ hipotezi firmanın diğer kurumlara göre rekabet avantajının firma inovasyon performansı üzerindeki etkisini temsil etmektedir. Bu ilişki için yol katsayısı (.004) pozitif ve istatistiksel olarak anlamlıdır. Bu nedenle $\mathrm{H}_{3}$ hipotezi desteklenmektedir.

\section{Sonuç}

Trabzon bölgesel inovasyon sisteminin Trabzon'da faaliyet gösteren firmaların inovasyon performansları üzerindeki etkisini incelemeyi amaçlayan bu çalışmada, Yapısal Eşitlik Modellemesi Analizi kullanılmıştır. KOSGEB tarafından desteklenen ve Trabzon Ticaret ve Sanayi Odasi tarafindan uygulanan “Trabzon'da Yenilikle Geleceğe Projesi" kapsamında yapılan "Ar-Ge ve Yenilik Anketi" Trabzon il sınırları içinde faaliyet gösteren, Trabzon Ticaret ve Sanayi Odası'na kayıtlı 160 firmaya uygulanmıştır.

Literatüre dayalı olarak oluşturulan araştırma modelinde bağımlı değişken firma inovasyon performansı, bağımsız değişkenler ise diğer kurumlarla yapılan işbirliği, ekosistemden kaynaklanan engeller ve rekabet avantajıdır.

Çalışma sonuçlarına göre, parametre tahminleri sonucunda hipotezler reddedilememiştir. Yol katsayılarına bakılarak rekabet ve işbirliği değişkenlerinin inovasyon performansı üzerinde pozitif, engeller değişkenin ise inovasyon performansı üzerinde negatif ve istatistiksel olarak anlamlı etkileri olduğu tespit edilmiştir. Elde edilen bulgular inovasyon sistemleri teorisi ile örtüşmektedir.

Çalışmadan elde edilen bulgular doğrultusunda inovasyon performanslarını arttırmak isteyen firmalara aşağıdaki tedbirler önerilmektedir:

- $\quad$ İşbirliğinden sağlanan fiziksel, zihinsel ve mali kaynaklar firma inovasyon performansını olumlu yönde etkilediğinden, firmaların söz konusu kaynaklara ulaşabilmesi için işbirliğine daha fazla önem vermelidirler.

- $\quad$ Ekosistem kaynaklı en önemli engeller teknolojik bilgi yetersizliği, nitelikli işgücü eksikliği ve inovasyon konusunda işbirliği eksikliği olarak görülmektedir. Firmaların bu engelleri aşabilmeleri için, emeğin eğitime teşvik edilmesi, nitelikli işgücü çekimi için cazip şartların sağlanması ve yine teknolojik bilgi ve inovasyon konusunda özellikle bilgi kurumlarıyla işbirliğine önem verilmelidir.

- $\quad$ Ekosistemde firmanın en önemli rekabet avantajları güvenilirliği ve müşterilerin yeni ürün ve hizmetlere erişebilirliğidir. $\mathrm{Bu}$ açıdan değerlendirildiğinde firmalara müşterilerde güven yaratabilmeleri ve bilgi-iletişim teknolojilerini verimli kullanarak yeni ürün ve hizmetlere ulaşımı kolaylaştırmaları önerilmektedir. 


\section{Kaynakça}

Aghion, P., Bloom, N., Blundell, R., Griffith, R. ve Howitt, P. (2005). Competition and Innovation: An Inverted-U Relationship. Quarterly Journal of Economics, 120(2), 701-728.

Ahn, S. (2002). Competition, Innovation and Productivity Growth: A Review of Theory and Evidence, OECD Economics Department Working Papers, No. 317, OECD Publishing, Paris.

Akçomak, İ. S. ve Kalaycı, E. (2016). Ar-Ge ve Yeniliğin Ölçümü ve Ar-Ge ve Yenilik Anketi Verilerinin Araştırmada Kullanılması, Bilim, Teknoloji ve Yenilik Kavramlar, Kuramlar ve Politika içinde, 107-126, 1. Bask1, Mega Basım Yayın: İstanbul.

Aschhoff, B. ve Schmidt, T. (2008). Empirical Evidence on the Success of R\&D Cooperation-Happy Together? Review of Industrial Organization, 33(1), 41-62.

Asheim, B. ve Isaksen, A. (1997). Location, Agglomeration and Innovation: Towards a Regional Innovation System in Norway, European Planning Studies, 5(3), 299-330.

Asheim, B., Isaksen, A., Nauwelaers, C. ve Tötdling, F. (2003). Regional Innovation Policy for Small-Medium Enterprises, US: Edward Elgar.

Asheim, Bjørn T., Coenen, L. ve Henning, M. (2003). Nordic SMEs and Regional Innovation Systems. Final Report, Department of Social and Economic Geography Lund University Sweden.

Asheim, Bjørn T. ve Isaksen, Arne (2002). Regional Innovation Systems: The Integration of Local 'Sticky'and Global 'Ubiquitous' Knowledge. The Journal of Technology Transfer, 27 (1), 77-86.

Bagozzi, R. P. ve Yi, Y. (1988). On the Evaluation of Structural Equation Models. Journal of the Academy of Marketing Science, 16, 74-94.

Bartels, F.L., Koria, R., Torriero, A., Cravenna, B. ve Strinati, C. (2014). National Systems of Innovation: a Structural Model Analysis of Efficacity-The Case of Ghana. Innovation Forum, Paris.

Becker, W. ve Dietz, J. (2004). R\&D Cooperation and Innovation Activities of firms-Evidence for the German Manufacturing Industry. ResearchPolicy, 33(2), 209-223.

Bentler, P. M. ve Yuan, K. (1999). Structural Equation Modeling with Small Samples: Test Statistics. Multivariate Behavioral Research, 34 (2), 181-197.

Berchicci, L. (2013). Towards An open R\&D System: Internal R\&D Investment, External Knowledge Acquisition and Innovative Performance. Research Policy, 42(1), 117-127 
Blundell, R.,Griffth, R. ve Reenen, J. V. (1999). Market Share, Market Value and Innovation in a Panel of British Manufacturing Firms. Review of Economic Studies, 66, 529-554.

Braczyk, H. J., Cooke, P. ve Heidenreich, M. (1998). Regional Innovation Systems, London: UCL Press

Brioschi, F., Brioschi, M. S. ve Cainelli, G. (2002). From the Industrial District to the District Group: An Insight into the Evolution of Capitalism in Italy. Regional Studies, 36(9), 1037-1052.

Bullinger, H. J., Auernhammer ve K., Gomeringer, A. (2004). Managing Innovation Networks in the Knowledge-driven economy, International Journal of Production Research, 42(17), 3337-3353

Burmaoğlu, S. ve Şeşen, H. (2011). Türk Firmalarının Organizasyonel İnovasyon Yeteneğini Etkileyen Faktörler Üzerine bir Araştırma. Ankara Üniversitesi SBF Dergisi, 66(4), 1-20.

Coad, A., Pellegrino, G. ve Savona, M. (2016). Barriers to Innovation and Firm Productivity, Economics of Innovation and New Technology, 25(3), 321-334.

Cooke, Philip (1992). Regional Innovation Systems: Competitive Regulation in The New Europe. Geoforum, 23(3), 365-382.

Corchuelo B.ve Mesías F. J. (2015). Innovation Policies and Barriers to Innovation: An Analysis in Extremadura (Spain) in Handbook of Research on Internationalization of Entrepreneurial Innovation in the Global Economy, 3050, IGI Global.

Darai, D., Sacco, D. ve Schmutzler, A. (2010). Competition and Innovation: An Experimental Investigation. Experimental Economics, 13, 439-460.

Fariaa, P., Lima, F. ve Santos, R. (2010). Cooperation in Innovation Activities: The Importance of Partners. Research Policy, 39(8), 1082-1092.

Diez, J. D. (2000). Innovative Networks in Manufacturing: Some Empirical Evidence from the Metropolitan Area of Barcelona.Technovation, 20(3), 139150.

Doloreux, D. (2004). Regional Networks of Small and Medium Sized Enterprises: Evidence from the Metropolitan Area of Ottawa in Canada. European Planning Studies, 12(2), 173-189.

Estrada, I., Faems, D.ve de Faria, P. (2016). Coopetition and Product Innovation Performance: The Role of Internal Knowledge Sharing Mechanisms and Formal Knowledge Protection Mechanisms. Industrial Marketing Management, 53, 5665 . 
Findik, B. ve Beyhan, B. (2015). The Impact of External Collaborations on Firm Innovation Performance: Evidence from Turkey. Procedia - Social and Behavioral Sciences, 195, 1425-1434.

Floyd, F. J. ve Widaman, K. F. (1995). Factor Analysis in the Development and Refinement of Clinical Assessment Instruments. Psychological Assessment, 7(3), 286-299.

Freeman, C. (1987). Technology Policy and Economic Performance-Lessons from Japan, London: Pinter.

Freeman, C. (2002). Continental, National and Sub-National Innovation Systems Complementarity and Economic Growth, Research Policy, 31, 191-211.

Fritsch, Michael (2001). Co-operation in Regional Innovation Systems. Regional Studies, 35(4), 297-307.

Galia, F. ve Legros, D. (2004). Complementarities between Obstacles to Innovation: Evidence from France. Research Policy, 33(8), 1185-1199.

George, D. ve Mallery, P. (2010). SPSS for Windows Step by Step: a Simple Guide and Reference 17.0 Update., Boston: Pearson.

Gertler, M. ve Asheim, B. (2005). The Geography of Innovation: Regional Innovation Systems, in The Oxford Handbook of Innovation, Oxford: Oxford University Press.

Hadjimanolis, A., (1999). Barriers to innovation for SMEs in a small less developed country (Cyprus). Technovation, 19(9), 561-570.

Hartono, A. ve Kusumawardhani, R. (2018). Innovation Barriers and Their Impact on Innovation: Evidence from Indonesian Manufacturing Firms. Global Business Review, 20(5), 1-18.

Hölzl, W. ve Janger, J. (2013). Does the Analysis of Innovation Barriers Perceived by High Growth Firms Provide Information on Innovation Policy Priorities? Technological Forecasting and Social Change, 80(8), 450-1468.

Hu, L. T. ve Bentler, P.M. (1999). Cut off Criteria for Fit Indexes in Covariance Structure Analysis: Conventional Criteria Versus. Structural Equation Modeling, 6 (1), 1-55.

Kalay, F., Tuncer, C. O., Kızıldere, C. ve Arslan Kalay, H. (2015). Stratejik İnovasyon Yönetimi Uygulamalarının Firma İnovasyon Performans1 Üzerindeki Etkileri. Bilgi Ekonomisi ve Yönetimi Dergisi, 10(2), 67-77.

Kaminski, P.C., de Oliveira, A. C. ve Lopes, T.M., (2008). Knowledge Transfer in Product Development Processes: A Case Study in Small and Medium Enterprises (SMEs) of the Metal-Mechanic Sector from São Paulo, Brazil. Technovation, 28(1-2), 29-36. 
Karakaya, A., Azade, S., Perçin, S. (2018). Türk İmalat Sanayinde Performans, İnovasyon ve Rekabet Arasındaki İlişki. Uluslararası Ekonomi ve Yenilik Dergisi, 4 (1) 2018, 39-59.

Katila, R. (2000). Measuring innovation performance. International Journal of Business Performance Measurement, 2: 180-193.

Larsson, S. ve Malmberg, A. (1999). Innovations, Competitiveness and Local Embeddedness. Geografiska Annaler Series B: Human Geography, 81(1), 1-18.

Liao, T. ve Rice, J. (2009). Innovation Investments, Market Engagement and Financial Performance: a Study Among Australian Manufacturing SMEs. Research Policy, (39), 117-125.

Liefner, I., Hennemann,S. ve Xin, L. (2006). Cooperation in the Innovation Process in Developing Countries: Empirical Evidence from Zhongguancun, Beijing. Environment and Planning A, 38(1), 111-130.

Lundvall, B. (1992). National System of Innovation: Towards a Theory of Innovation and Interactive Learning, London: Pinter.

Madeira, M. J., Carvalho, J., Miguel Moreira, J.R., Duarte, F. AP. ve de São Pedro Filho, F. (2017). Barriers to Innovation and the Innovative Performance of Portuguese Firms. Journal of Business, 9(1), 2-22.

Madrid-Guijarro, A., Garcia, D. ve Van Auken, H. (2009). Barriers to Innovation Among Spanish Manufacturing SMEs. Journal of Small Business Management, 47(4), 465-488.

Nelson, R. (1993). National Systems of Innovation: A Comparative Analysis, Oxford: Oxford University Press.

Nevo, A. (2001). Measuring Market Power in the Ready-to-Eat Cereal Industry. Econometrica, 69(2), 307-342.

Nickell, S. J. (1996). Competition and Corporate Performance. Journal of Political Economy,104, 724-746.

Nieto, M. J. ve Santamaria, L. (2007). The Importance of Diverse Collaborative Networks for the Novelty of Product Innovation. Technovation. 27(6-7), 367377.

Özgür Güler, E. ve Kanber, S. (2011). İnovasyon Aktivitelerinin İnovasyon Performansı Üzerine Etkileri: İmalat Sanayii Uygulaması. Çukurova Üniversitesi Sosyal Bilimler Enstitüsü Dergisi, 20(1), 61-76.

Petrin, A. (2001). Quantifying the Benefits of New Products: The Case of the Minivan. NBER Working Paper Series, No.8227 
Poruchnyk, A. ve Brykova, I. (2006). The Regional Innovation System as the Basis for Elevating the International Competitive Status of National Regions. Kyiv: Kyiv National Economic University.

Pourkiani, M., Farahabadi, H. S. ve Komak, M. D. (2013). Organizational Innovation, Barriers and Factors. European Online Journal of Natural and Social Sciences, 2 (3), 724-731.

Robin, S ve Schubert, T. (2013). Cooperation with Public Research Institutions and Success in Innovation: Evidence from France and Germany. Research Policy, 42(1), 149-166.

Sağ, S., Sezen, B. ve Güzel, M. (2016). Factors That Motivate or Prevent Adoption of Open Innovation by SMEs in Developing Countries and Policy Suggestions, Procedia - Social and Behavioral Sciences, 235, 756-763.

Schmutzler, A. (2009). Is Competition Good for Innovation? A Simple Approach to an Unresolved Question. Foundations and Trends in Microeconomics, 5 (6), $355-428$.

Schumacker, R. E. ve Lomax, R. G. (2010). A beginner's guide to structural equation modeling. New York: Taylor and Francis Group.

Seyfettinoğlu, Ü. K. ve Taşdoğan, C. (2014). Açık İnovasyon ve Firma Performansı İlişkisi: Türkiye Gıda ve İçecek Sanayi Örneği. İktisat İşletme ve Finans, 29(338), 9-38.

Simona Iammarino \& Francesca Sanna-Randaccio \& Maria Savona, 2007. "The perception of obstacles to innovation. Multinational and domestic firms in Italy," Working Papers of BETA 2007-12, Bureau d'Economie Théorique et Appliquée, UDS, Strasbourg.

Tomlinson, P. R. ve Fai, F. M. (2013). The Nature of SME Co-operation and Innovation: a Multi-Scalar and Multi-Dimensional Analysis. International Journal of Production Economics, 141 (1), 316-326.

Wang, Y. (2016). What are the Biggest Obstacles to Growth of SMEs in Developing Countries? - An Empirical Evidence from an Enterprise Survey. Borsa Istanbul Review, 16(3), 167-176.

Weston, R. ve Gore, P. A. (2006). A Brief Guide To Structural Equation Modeling. The counseling psychologist, 34(5), 719-751.

Wiig, Heidi (1996). An Empirical Study of the Innovation System in Finnmark. STEP Report Series No:199609, Studies in Technology, Innovation and Economic Policy, ISSN 0804-8185. 
Wiig, Heidi ve Wood, Michelle (1995). What Comprises a Regional Innovation System? An Empirical Study. Regional Futures: Past and Present, East and West: Regional Association Conference: Gothenburg, Sweden.

Wu, J. (2014). Cooperation with Competitors and Product Innovation: Moderating Effects of Technological Capability and Alliances with Universities. Industrial Marketing Management, 43(2), 199-209

Zeng, S. X., .Xie X.M. ve Tam, C. M. (2010). Relationship between Cooperation Networks and Innovation Performance of SMEs, Technovation, 30(3), 181-194. 